\title{
Building the regenerative medicine workforce of the future: an educational imperative
}

\author{
Saranya P Wyles ${ }^{1,2}$ \& Andre Terzic*,2,3,4,5 \\ ${ }^{1}$ Mayo Clinic Department of Dermatology, Rochester, MN 55905, USA \\ ${ }^{2}$ Mayo Clinic Center for Regenerative Medicine, Rochester, MN 55905, USA \\ ${ }^{3}$ Mayo Clinic Department of Cardiovascular Medicine, Rochester, MN 55905, USA \\ ${ }^{4}$ Mayo Clinic Department of Molecular Pharmacology \& Experimental Therapeutics, Rochester, MN 55905, USA \\ ${ }^{5}$ Mayo Clinic Department of Clinical Genomics, Mayo Clinic, Rochester, MN 55905, USA \\ *Author for correspondence: terzic.andre@mayo.edu
}

\begin{abstract}
“This emerging discipline has therefore rapidly matured to traverse from the fringe of breakthrough technological achievements to the very core of medical education and future evidence-based practice - one small step for medicine, a giant leap for regenerative care."
\end{abstract}

First draft submitted: 13 May 2019; Accepted for publication: 6 June 2019; Published online: 25 July 2019

Keywords: discovery-translation-application • education • healthcare $\bullet$ healthcare workforce $\bullet$ implementation $\bullet$ regenerative medicine $\bullet$ training $\bullet$ translation

Regenerative science is a transformative driver of next-generation treatment options, (re)defining the forefront of modern medicine. Fueled by disruptive technologies, the reach of medical practice is poised to expand - beyond the more traditional boundaries of patient care - into the new reality of enhanced innate regeneration to restore form and function. Scientific and clinical advances point, however, to an educational void in guiding the prospect of regenerative care. Indeed, today, the healthcare workforce remains only partially informed and generally is ill equipped in navigating the emergent regenerative medicine landscape. It is therefore an educational imperative to augment the practitioners' literacy, competency and overall proficiency in new knowledge and specialized skill sets mandated by the incumbent regenerative era of tomorrow.

\section{Emerging landscape}

The milestone 21st Century Cures Act garnered support from the US Congress to accelerate the next-generation of medical innovation to address patient needs [1]. At a global scale, regenerative readiness is embraced with the commission of actionable paradigms that reshape healthcare avenues. The prospect of transforming standard-ofcare practices through the 'build, rebuild or repair' lens of regenerative medicine aims to reclaim patient health standards compromised by disease [2]. Ongoing clinical trial-validation includes salient examples such as with regenerative chimeric antigen receptor (CAR) T-cell immunotherapies to address hematological malignancies; stem cell transplantation to treat spinal cord injury; facial reanimation in plastic and reconstructive surgery; osteochondral grafts in bone and cartilage repair; platelet-rich plasma interventions in physical medicine and rehabilitation; cell and acellular therapies for degenerative diseases in neurology, cardiology, nephrology or vascular surgery; new organ regeneration; and tissue bio-printing for pathologies in head and neck, thoracic and colorectal surgery. Technological advances in regenerative treatments have led to an insurgence of patients seeking these therapies [3], revealing unmet impending delivery requirements from healthcare providers. Upholding the promise to deliver validated regenerative solutions prompts the question: are healthcare professionals ready to practice in this emerging field? 


\section{Readiness gap}

As the regenerative horizon approaches the vanguard of future medicine [4], the paucity of adequately trained healthcare providers in regenerative principles and practices is recognized [5]. Physician readiness is the ability to accurately assess patient safety of new repair paradigms and effectively apply validated technologies for unmet needs. The broadening lexicon of disruptive technologies suggests scientific maturity of regenerative concepts - previously at the fringe of guiding clinical practice - ripened for core training of all patient care providers [6,7]. With this evolution, there is a new reality of understanding the clinical-grade supply chain ecosystem with ultimate goal to deliver regenerative care in the future of scientific and medical practice [8]. Indeed, the shifting composition of the healthcare workforce necessitates the curation of a comprehensive, learner-centered, patient-focused regenerative curriculum that aligns with evolving technological trends to advance the scientific foundations of medicine. This healthcare provider readiness initiative behooves institutions to educate, develop and deploy a skilled next-generation workforce, primed to practice in the forthcoming era of regenerative medicine.

Historically, medical education in regenerative sciences has been confined to scholarly concepts within developmental biology, embryology and cell biology. In the past, key guiding innate regenerative principles permeated clinical practice through limited therapeutic avenues, for example, bone marrow transplantation and surgical flap reconstruction. Today, rapid biological and technological advances aimed at targeted repair of disease pathobiology and organ restoration provide a regenerative blueprint to tailor patient-specific needs in a large-scale, standardized method. In this 'regeneration for all' landscape, clinical development efforts have been identified as: validation of standard operation procedures needed for manufacturing; establishment of FDA regulatory pathways to expedite studies; and optimization of design and execution of clinical trial protocols [9]. Realization of this 'biopotentiated' healthcare ecosystem in parallel with advancing collateral fields (i.e., material sciences, tissue engineering, nanomedicine, etc.) necessitates systematic introduction to this transdisciplinary field. New education trends should therefore aim to introduce disruptive technologies without disrupting pathways across the discovery-translationapplication platform.

\section{Education mission}

The rapidly materializing (r)evolution of regenerative sciences into patient-ready clinical practice options [10] underscores the necessity to establish rigorous training programs tailored for the build-out of a contemporary healthcare workforce. An educational prototype to address physician-in-training preparedness was recently rolled out and tested [11]. Built across the discovery-translation-application scope [12], this education blueprint integrates a comprehensive matrix to incorporate regenerative medicine principles with real-world experiences in bench-tobedside translation, clinical-grade bio-manufacturing, regulatory approval and validation of regenerative procedures, culminating in the integration of best regenerative practices within curative patient care algorithms [13]. The regenerative medicine curriculum developed for medical students showcases a playbook for physician trainees [11] - major stakeholders of the evolving healthcare workforce responsible for regenerative care implementation. As such, adoption of knowledge early in medical training followed by longitudinal reinforcement during advanced clinical clerkships, residency electives and fellowship courses contributes to building a specialized workforce ready to practice informed regenerative care across specialties. Training opportunities inclusive of the shifting landscape of advanced practitioners will also be required to more broadly and systematically engage healthcare professionals [14].

In developing a curriculum focused on the 'from the patient to the patient' paradigm, new competencies in disruptive regenerative innovation should be recognized to occur in parallel with the diverse and digital healthcare environment. Training the next-generation workforce expands beyond traditional approaches, aimed at developmental biology pathways, and into multilevel systems interrogation and integration of disease complexity leveraging clinical experience (i.e., 3D bioprinting). Indeed, the discovery-translation-application training model provides unique opportunities for reverse translation to refine new information and optimize the decision support system for the translation of molecular insights into clinically applicable solutions [15]. Participation by trainees in collaborative, multidisciplinary teams of physician-investigators, engineers and material scientists should be encouraged in the setting of emerging biotechnology expanding the reach of current practices. Longitudinal training therefore involves transdisciplinary faculty across medical, surgical, radiological and laboratory medicine specialties that incorporate disruptive innovation and deep learning to better predict/prevent/cure degenerative disease and address unmet patient needs. The newly educated community of regenerative practitioners is collectively poised to proactively optimize health span across life span [16]. 


\section{Conclusion}

In the goal of fostering education-driven practice advancement, continual underpinning across the clinical training spectrum allows trainees to enrich their medical science foundation while remaining at the vanguard of proven trends and validated, standardized clinical experiences. This emerging discipline has therefore rapidly matured to traverse from the fringe of breakthrough technological achievements to the very core of medical education and future evidence-based practice - one small step for medicine, a giant leap for regenerative care.

\section{Financial \& competing interests disclosure}

Andre Terzic receives funding from the NIH (USA; grant number HL134664), Marriott Family Foundation, Michael S and Mary Sue Shannon Family, Russ and Kathy Van Cleve Foundation, Mayo Clinic Center for Regenerative Medicine and Regenerative Medicine Minnesota. The authors have no other relevant affiliations or financial involvement with any organization or entity with a financial interest in or financial conflict with the subject matter or materials discussed in the manuscript apart from those disclosed.

No writing assistance was utilized in the production of this manuscript.

\section{Open access}

This work is licensed under the Attribution-NonCommercial-NoDerivatives 4.0 Unported License. To view a copy of this license, visit http://creativecommons.org/licenses/by-nc-nd/4.0/

\section{References}

1. Marks P, Gottlieb S. Balancing safety and innovation for cell-based regenerative medicine. N. Engl. J. Med. 378(10), 954-959 (2018).

2. Hargraves IG, Behfar A, Foxen JL, Montori VM, Terzic A. Towards regeneration: the evolution of medicine from fighting to building. Br. Med. J. 361(k1586), 1-3 (2018).

3. Von Tigerstrom B. Regulating the advertising and promotion of stem cell therapies. Regen. Med. 12(7), 815-826 (2017).

4. Blau HM, Daley GQ. Stem cells in the treatment of disease. N. Engl. J. Med. 380(18), 1748-1760 (2019).

5. Knoepfler PS. Call for fellowship programs in stem cell-based regenerative and cellular medicine: new stem cell training is essential for physicians. Regen. Med. 8(2), 223-225 (2013).

6. Schulman IH, Suncion V, Karantalis V, Balkan W, Hare JM; Cardiovascular Cell Therapy Research Network. Clinical research skills development program in cell-based regenerative medicine. Stem Cells Transl. Med. 4(2), 118-122 (2015).

7. Webster A. Regenerative medicine and responsible research and innovation: proposals for a responsible acceleration to the clinic. Regen. Med. 12(7), 853-864 (2017).

8. Knoepfler PS. Mapping and driving the stem cell ecosystem. Regen. Med. 13(7), 845-858 (2018).

9. Behfar A, Terzic A. Regeneration for all: an odyssey in biotherapy. Eur. Heart J. 40(13), 1033-1035 (2019).

10. Shapiro SA, Smith CG, Arthurs JR, Master Z. Preparing regenerative therapies for clinical application: proposals for responsible translation. Regen. Med. 14(2), 77-84 (2019).

11. Wyles SP, Hayden RE, Meyer FB, Terzic A. Regenerative medicine curriculum for next-generation physicians. NPJ Regen. Med. 4, 3 (2019).

12. Terzic A, Harper CM, Jr, Gores GJ, Pfenning MA. Regenerative medicine blueprint. Stem Cells Dev. 22(Suppl. 1), 20-24 (2013).

13. Terzic A, Pfenning MA, Gores GJ, Harper CM, Jr. Regenerative medicine build-out. Stem Cells Transl. Med. 4(12), 1373-1379 (2015).

14. Auerbach DI, Staiger DO, Buerhaus PI. Growing ranks of advanced practice clinicians - implications for the physician workforce. $N$. Engl. J. Med. 378(25), 2358-2360 (2018).

15. Waldman SA, Terzic A. Managing innovation to maximize value along the discovery-translation-application continuum. Clin. Pharmacol. Ther. 101(1), 8-12 (2017).

16. Waldman SA, Terzic A. Healthcare evolves from reactive to proactive. Clin. Pharmacol. Ther. 105(1), 10-13 (2019). 